\title{
A System Approach For Defining Data Center Value Proposition
}

\author{
M. Hossain Heydari, James Madison University \\ Faramarz Damanpour, James Madison University \\ Ayman Nassar, Intercontinental Networks
}

\begin{abstract}
Organizations invest heavily in IT infrastructure and the data center's share of these investments is not marginal. Organizations face the challenge of justifying capital and operational spending on these facilities and often measuring the performance of data center is ignored. Performance measurements focus on analyzing the performance of servers and software applications rather than that of the impact of the data center on the organization. Various methods that have been currently used do not convey the actual value of the data center and do not provide accurate predications of its benefit and expected performance. This report introduces a method to define the value proposition of a data center using a set of metrics that provide measures for a number of variables that define the behavior and outcomes of a data center. An analysis of the data center behavior and outcome will provide a system model from which stakeholder value can be defined.
\end{abstract}

\section{INTRODUCTION}

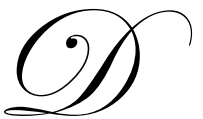

ata centers have appeared in the early days of computing with the arrival of giant computing platforms also known as mainframes. These huge computing platforms were noisy, used large tape drives, produced huge amounts of heat and required special facilities to host and operate them. As the technology developed, computing platforms became smaller, faster and less energy hungry. In the mid 1980s the commercial availability of local area network technologies has contributed to the widespread idea of distributed computing in the enterprise. Server deployments across campuses and enterprises replaced centralized data centers.

By the early nineties most organizations had departmental server closets or rooms which would contain file servers, print servers, and even departmental application servers. The quick developments in the telecommunications and networking fields and the increased security risks, in addition to the complexity of managing large-scale distributed computing networks has led organizations to rethink their computing strategy and whether distributed computing was really worth the price.

Today data centers have become a major point of interest in the technology industry. However the mainframe is no longer the main thought that comes to mind when mentioning data centers but rather condensed blade computing, multi-vendor, multi-environment open computing systems, on-demand computing features and virtualization, outsourcing and utility computing to name a few. Furthermore, thousands of data centers in North America contain dense rows of rack-mounted servers and routers, ranging in size from $5,000 \mathrm{ft}^{2}$ to $400,000 \mathrm{ft}^{2}$, and they confidently promise clients over 99 percent uninterrupted operation [Elliott 2001]. These data centers are besides the thousands of private enterprise centers serving the information access and analysis needs of the organizations in which they operate.

Traditionally, studies have focused on IT operations performance management and value analysis, or IT infrastructure investments and very little focus has been provided to data centers. Trends in technology and in business needs has transformed the data center from a purely IT operations unit into a unit which encompasses a scope comprising IT operations, infrastructure investments, project planning and management, and service 
management functions. This transformation has demanded skills and knowledge based services and provides both pure and product-based service types as depicted in Figure 1.

In addition, data centers are considered both an IT infrastructure as well as an IT operational environment, and transformed from batch job processing into real-time value added services. To address these value-added data center services the underlying architecture has undergone major changes. Some of the major trends in the industry are self-management, custom services, integrated security, dynamics applications, real time capabilities, intelligent facilities, virtualized infrastructure, and grid operating system. Two main approaches that exist in the industry are broken down into qualitative and quantitative approaches. Each has its merits and disadvantages. The best approach is a mix of the two, which considers external factors affecting the data center, internal attributes of the data center and temporal factors when assessing the value proposition of data center.

To accomplish this task, a three dimensional value proposition approach is necessary. 3 DVP utilizes several well-known systems engineering concepts such as system architecture, system dynamics, causation effects and heuristics. Therefore, the data center can be analyzed as an integrated service system, comprising of various subsystems and possessing well-defined attributes under a well-defined condition.

Figure 1

Typical Data Center Services

\begin{tabular}{c|c|c|}
\multicolumn{1}{c}{} & \multicolumn{1}{c|}{ Knowledge-based } & Skill-based \\
\cline { 2 - 3 } Pure & Forecasting & Job Execution \\
Service & Planning & Backups \\
& Consulting & Monitoring \\
& & Escalation \\
\cline { 2 - 3 } $\begin{array}{c}\text { Product-based } \\
\text { Service }\end{array}$ & & Printing \\
& Real-time Reporting & Scanning \\
& & Custom e-Formatting \\
\cline { 2 - 3 } & & Tips \\
\hline
\end{tabular}

\section{REVIEW OF LITERATURE}

Various methods for appraising projects and investments including technology and IT-based have been developed in the financial industry and documented by Josh Lerner (2000) and Janet Smith and Richard Smith (2000), using the net present value (NPV), the adjusted present value (APV), the risk-adjusted discount rate (RADR) method, the certainty equivalent (CEQ) method, the venture capital method, the first Chicago method, return on investment (ROI) and total cost of ownership (TCO). Although there are differences among these methods, they all share a common concept which is that these methods are heavily based on hard historical measured data used to forecast future expectations disregarding external and internal factors and behavioral attributes, hence lacking the complete and accurate reflection of the true value of an IT investment.

Attempts to improve IT-based infrastructure investment valuations and assessments are inevitably influenced by some underlying values and assumptions. Renkema (2000) indicated that the value proposition has a much broader scope than just performance, and the reader improvements in organizational practices should always take into account two types of designs, referred to as a "soft design" and "hard design." This belief relates closely to "hard systems thinking" and "soft systems thinking" discussed by Checkland (1989) and Rosenhead (1989) respectively. It also relates to the two well-known "quantitative" and "qualitative" research methods which are based on the use of hard quantifiable data collected from measurements or surveys; and understanding of organizational reality as soft social constructions in which continuous processes of sense-making take place respectively [Renkema 2000]. Renkema (2000) concluded that evaluating true business value of IT is very difficult and that capturing the value of an IT-based infrastructure is often considered as the most critical and most complex part of managerial decision-making, moreover, as faster technological developments take place, it will become more important than ever before. He also stated that business value assessment of IT-based infrastructure is above all seen as a 
communicative stakeholder process in which both hard and soft data must be utilized and captured using relevant insights and instruments, and can not be solely dependent on standard finance-oriented appraisal techniques. Orlikowski and Baroudi (1996) have also performed a study of various research approaches and assumptions for analyzing IT in organizations.

Kaplan and Norton (1991) devised the balanced scorecard (BSC) method in 1991 and discussed it further in their publications 1996 and 2000. The BSC has gained wide acceptance across various industries. While BSC has flourished in the business sector more than others areas, it has still been applied and its concepts tried in other sectors such as non-profit organizations, education and government. Stewart and Carpernter-Hubin (2000-2001) illustrate BSC's use in studying the effectiveness of the education of a Community College environment, and Ruben (1999) applies BSC to rethink higher education excellence indicators. Federal Chief Information Officers Council (2001) provided an example of applying BSC in the Federal Government. The BSC method is used to measure the effectiveness and efficiency of an organization. The organization could be a business or a data center. It used to analyze the performance of a data center and it will allow the data center manager to align the operations of the data center to its mission and goals and eventually to those of the enterprise. BSC looks at the financial perspective, the customer perspective, in relationship to management perspective and disciplines.

The Applied Information Economics (AIE) method is another method used to analyze and measure IT investments value. It has been invented by Douglas Hubbard and distributed in March 2005. AIE is based on the principle that information reduces uncertainty, less certainty improves decisions and better decisions result in more effective actions, and finally effective actions improve mission results. A study conducted by the Federal CIO Council yielded that BSC is more suitable for building consensus within an organization and to clearly identify initiatives for system acquisition, development and implementation. The BSC strength was in aligning and fostering consensus for a proposed IT investment to the mission and goals of the Federal agency. BSC defined strategies to achieve mission results, and it is powerful tool in quantifying and estimating costs, benefits, in addition to risk and ROI. Users of the AIE methodology found it tough to comprehend due to its scientific and mathematical nature, however the performance measures were considered highly useful.

IBM has conduced research in the area of quantifying e-business initiatives value. The research has yielded a methodology known as the Risk and Opportunity Assessment and uses a tool called the Value Chain Modeling Tool [Grey 2003]. The Risk and Opportunity Assessment is based on 3 main steps. The first step is the data collection stage, where data requirements are defined, a data collection plan is developed, the data collection performed. Also background information about the initiative, assumptions and sources for the assumptions are documented. Monitoring and validation of the data collection process also take place during this phase. The second step is the modeling and analysis phase. This stage involves building a baseline model, defining drivers for the initiative from both a financial and an operational perspective, and developing various scenarios showing the various conditions in which the initiative might be impacted by. The final step is the development stage where cost-benefit analysis is performed, solutions selected and prioritized and action plans developed.

\section{STATEMENT OF PURPOSE}

Currently, various methods are used to analyze the performance of a data center such as the return on investment (ROI) method, the total cost of ownership (TCO) and the net present value (NPV) method. None convey the actual value of the data center and do not provide accurate predications of its benefit and expected performance. This report presents a new approach for defining the value proposition of a data center, using a set of metrics that provide measures for a number of variables that define the behavior and outcomes of a data center. The main aim of this research is to introduce a simple method for defining data center value proposition to the enterprise, with the goal of realizing an approach that reflects the strengths of traditional qualitative and quantitative methods using a systems-based method. A method for defining data center value proposition to an enterprise is proposed and discussed. The research also identifies and defines the major data center attributes and external conditions. The methodology utilizes techniques from systems engineering and technology marketing domains such as concepts of systems dynamics, and product positioning and marketing to define the relationships between the various data center 
attribute and condition variables. This new and innovative approach is the key contribution of this study to the current body of literature.

Two main approaches that exist in the industry are broken down into qualitative and quantitative approaches. Each has its merits and disadvantages. The report discusses the three dimensional value proposition (3DVP) approach which considers external factors affecting the data center, internal attributes of the data center and temporal factors when assessing the value proposition of data center. It allows for a mixing of qualitative and quantitative methods and hence ensures that it includes soft as well as hard factors in the value assessment. The 3DVP utilizes several well-known systems engineering concepts such as system architecture, system dynamics, causation effects and heuristics.

A community college data center was used as a case study and a research subject where the team applied the 3DVP approach to identify metrics that could be used to define the value proposition. Most metrics identified using the 3DVP approach were more significant than those previously identified and used by the college, and provided more understanding of the true value of the data center from the perspective of the college's main stakeholder, the student.

Hypothesis: The data center's value proposition is function of a set of relative variables identifying its characteristics, and the conditions in which it operates. An analysis of these variables to study dependencies can reflect the worthiness or importance of the data center to a specific stakeholder of the data center at a specific point in time.

The method presented in this paper is called the Three Dimensional Value Proposition Chart and is based on the simple fact that the value of any entity or system is dependent on three main types of variables, internal variables (the attributes and characteristics) of the entity, external variables (conditions and external factors) impacting the entity, and the temporal effect represented in a varying time interval as discussed earlier and illustrated in Figure 3. This proposed method is consistent with the concepts presented in other studies such as Porter (1998) where he links the value of an entity to that of a complete chain, both the inputs (external factors) and outputs (the result of internal factors and attributes, or the behavior of the system, in this case the data center).

Data center value proposition will comprise of a number of tasks:

- $\quad$ Defining the data center

- Defining a data center stakeholder

- $\quad$ Defining attributes of the data center of relevance to the stakeholder

- Defining conditions under which the data center exists

- $\quad$ Define the variables of most relevance and importance to the value proposition definition

- Use a mixed qualitative-quantitative analysis method to calculate the value proposition of the data center for the selected stakeholder

This report is organized into five sections and a number of appendices. Section 1 is a general introduction, section 2 provides an overview of value proposition and introduces an approach used to define value proposition. Section 3 discusses the three Dimensional Value Proposition and Data center attributes and conditions and section 4 applies the approach to a community college. Section 5 provides analysis of the findings and a summary of the work performed respectively.

\section{VALUE PROPOSITION MANAGEMENT STRATEGY}

Value proposition management is a complex process due to the dependence on a vast number of variables which could very well be inter-dependent and correlated. It carried out throughout the system development process, from system conception all the way to the end-of-life of the system or service. Value Proposition Management involves the following four phases throughout the life-cycle of a system: 
1. Value Definition: defines the keys variables that will be used to provide the differentiated value of a data center service.

2. Value development: allows the data center manager to identify methods and processes to realize value through the previously identified variables. The main aspects involved are: innovation, quality, strategy, management, and organization.

3. Value Measurement: consists of both qualitative and quantitative exercise to define accurate relationships among the various identified variables to assess the contribution of each towards the product's overall value.

4. Value Marketing and Communication: consists of strong marketing messages and value sharing communication with stakeholders -- customers and users. Again emphasis is to combine qualitative and quantitative approaches.

In order to develop and create value, the data center manager must work closely with the top administration and management of the enterprise to include the overall organizational mission, goals, and objectives. All organizational processes should be considered, and departments should be strongly involved to provide relevant details about actions and steps involved in the development of a business function which could be fully or partially serviced by the data center. These services are then defined and prioritized by the top management familiar with organizational business functions. The basic blocks for value creation presented in the Figure 2.

The data center manager is the main value developer for the data center and should bear in mind that stakeholders loyalty can be a contributor to value creation, and that they can be part of the value creation process, saving the business huge costs and time. By listening to stakeholders a value developer can develop innovative processes that allow the stakeholders to mass customize products or processes that offer stakeholders optimum value.

\section{THE THREE DIMENSIONAL VALUE PROPOSITION TOOL (3DVP)}

The Three Dimensional Value Proposition is based on the idea that the value of any system is dependent on three main types of variables: internal variables (the attributes and characteristics) of the entity, external variables (conditions and external factors) impacting the entity, and the temporal effect represented in a varying time interval. 3DVP is illustrated in Figure 3. As mentioned before, Value Proposition Management is a process consisting of both qualitative and quantitative analysis and research to identify the key attributes of a system that provide the optimum worthiness of a system to a specific set of system (stakeholders) under certain conditions at a certain point in time. We can hence state that the value of a system is a function of a set measurable attribute of a system under different conditions and at a specific point in time, and that these variables are only relevant to a certain group of stakeholders. The concepts [Nassar 2003] are not only applicable to product value proposition, but could also be applied to services provisioning and systems operation value proposition.

The first dimension deals with the attributes of the data center service itself. These attributes could be inherent in the materials used to develop the service, the technology embedded in the service offered, or processes used during the various service development phases. Examples of such service attributes are the quality of the service, type of subcomponents comprising the overall service, the novelty of the service, the level of innovation and how much of the service is retained at the end of its life, or how much of it is a product-based service.

The second dimension focuses on the conditions in which the service is offered. These are typically external factors that impact the service offering. Examples are the external ambient temperature, the amount of funding available in the market or industry, energy prices, the needs of the service users, market competition and other factors or conditions which do not define the behavior of the system offering the service. 
Figure 2

Basic Blocks For Value Creation

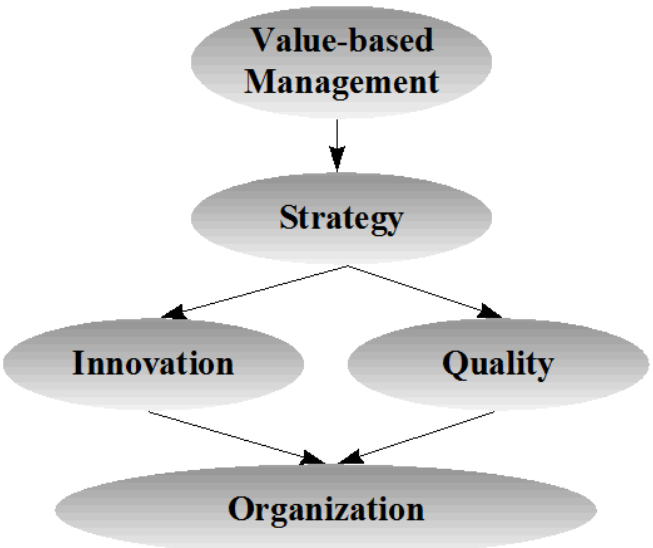

Figure 3

The Three Dimentions Of A System Value

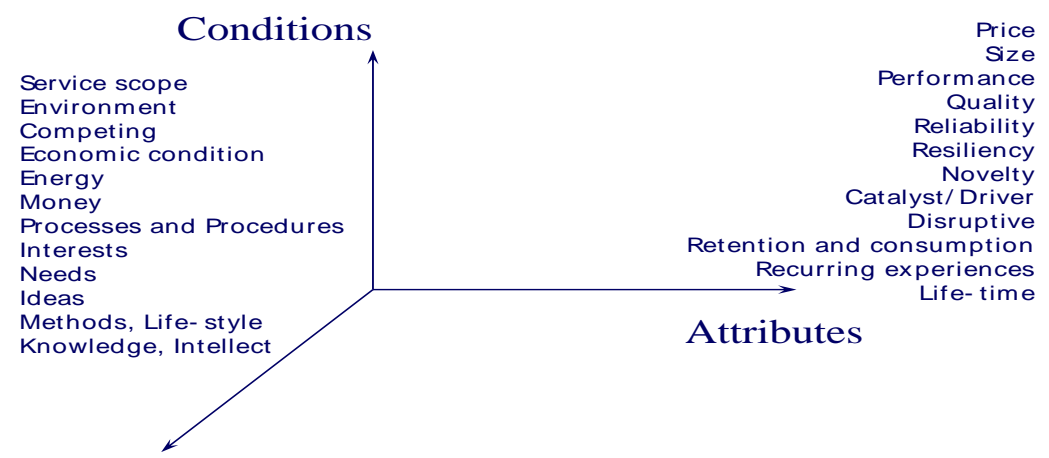

Time

A third dimension is the time, which means changes in the system value could vary with time due to variations in any of the attributes or factors defining the system or observed by the system respectively from a user's point of view. The specific attributes, factors and conditions will obviously vary from one system to another. The task of the experienced data center manager or chief information officer is to identify the most relevant and important attributes and factors, and to perform a value analysis based on those selected. The data center manager will then assign weights to each of the variables defined. Then, a range of values for each variable will be defined, comparisons will then be made and measurements recorded. Measurements could be repeated at various points in time to study changes in the value of a data center as a system, or any of its subsystems. The data center manager can baseline the value of a system at the point of system introduction and then periodically calculate the relative value of the system to other similar products in the market place. This method allows the system manager to mix quantitatively as well as qualitatively gauges to the value of a product. The method can be adapted and modified by system managers as wished by adding or removing variables as needed. 


\section{OPERATIONAL PERSPECTIVE - DATA CENTER ATTRIBUTES AND CONDITIONS}

The specific attributes of interest for a data center will obviously vary from one data center to another depending on the type of enterprise and the point of view of the stakeholder. The task of the experienced data center manager is to identify the most relevant and important attributes and to perform a value analysis based on those selected. The data center manager will then assign weights to each of the variables defined on the value chart. Also a range of values for each variable will be defined. Comparisons are then made and measurements recorded. Measurements could then be repeated at various points in time to study changes in the value of the data center. The data center manager can baseline the value of a data center service or function at the point of introduction and then periodically calculate the relative value of the function to other similar functions at the same data center or same function at other data centers. This method allows product managers to quantitatively as well as qualitatively gauge the value of a function.

One example is where different customer scenarios can be developed and hence different conditions and factors. The data center manager can have a set of values for the same service at the same point in time which is different depending on the stakeholder. This concept can also be extended to include all stakeholders instead of just limiting it to customers, and to the organization as a whole instead of just to the service provisioned and developed by the data center. In such case the CIO can achieve a comparative study of the various IT projects and activities value. It is crucial that data center managers and business leaders view value in a much bigger perspective than just the monetary aspect of their products and businesses respectively.

This study will identify the following data center attributes. A common characteristic among all these variables is that they are all endogenous variables of the data center.

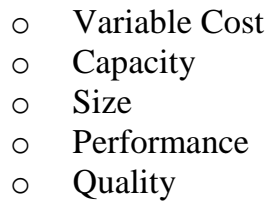

The second dimension defining the value of the data center is conditions. Conditions are the external influences that impact the data center and its characteristic behavior determined by its structure. It consists of 11 components:

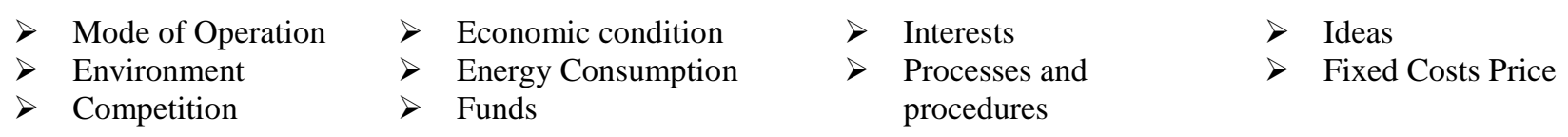

\section{DATA CENTER BEHAVIOR AND VARIABLE CAUSATION}

Figure 4 illustrates the causation among the various data center attributes and the conditions in which the data center might exist. S indicates that variable to the right changes in the same direction as the variable in the left (below) $\mathrm{O}$ means it changes in the opposite direction. Using the definitions discussed earlier for the data center attributes and conditions we make the following assumptions regarding the causation:

1. Variable cost affects the competitive strength of the data center. The more variable cost increases the more the competition increases and the data center becomes less attractive to its stakeholders. It can also be clearly noticed that as variable costs change it causes the data center funds to change in an opposite direction. 
2. An increase in capacity of the data center causes an increase in productivity and hence an increase in performance and a decrease in the unit cost of the data center output service therefore, causing a decrease in variable cost. Increasing data center causes the competitive strength of the data center to increase while competition decrease. An increase in data center capacity will most likely lead to an increase in energy consumption as well as increase in the number and complexity of processes and procedures due to the extra subsystems and elements.

3. Data center size affects cooling and heating and hence impacts variable cost and energy consumption in the same direction. Most often an increase in data center size will cause an increase in capacity and costs.

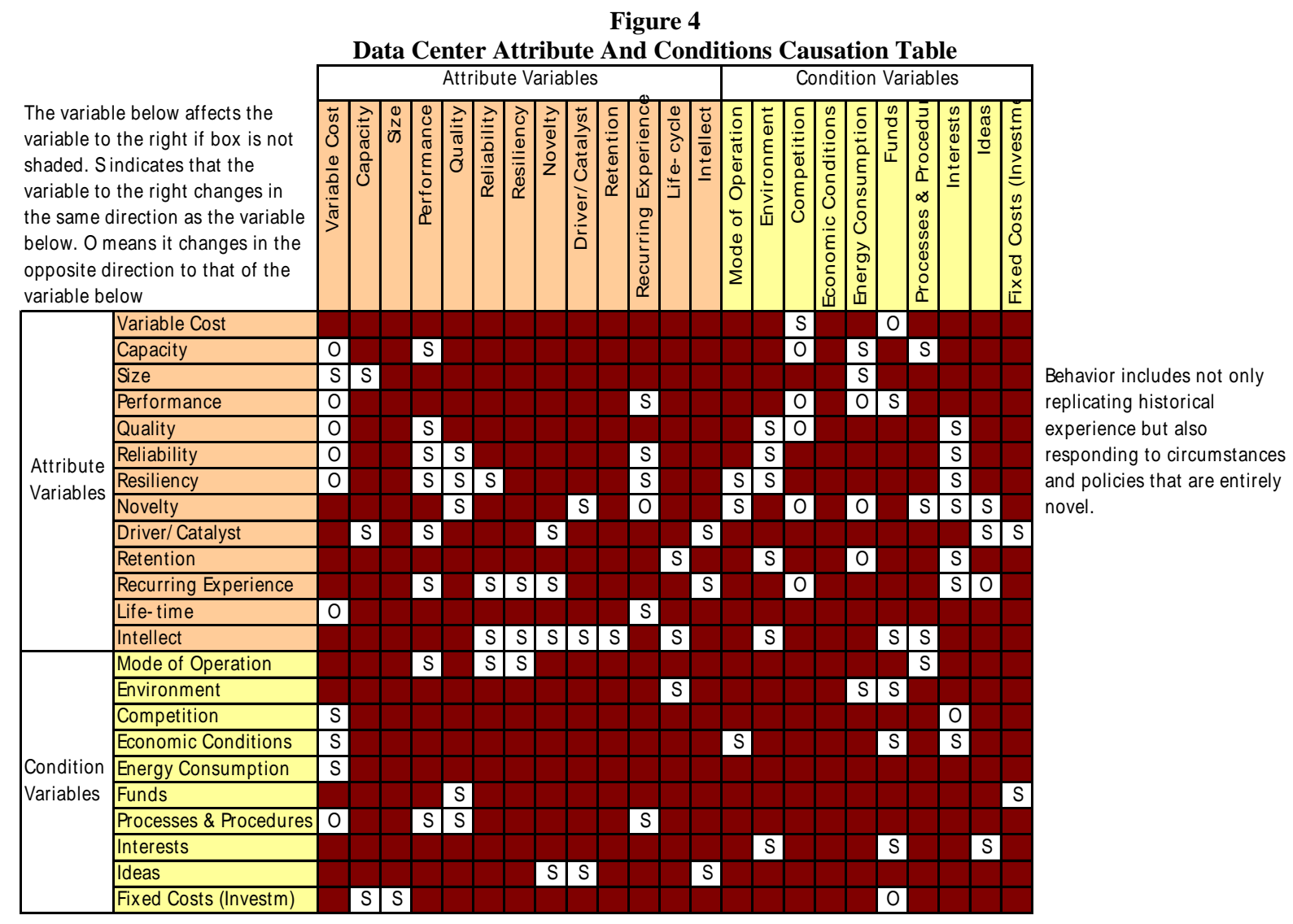

4. As mentioned earlier in this study we consider performance to be an outcome of productivity and quality (effectiveness and efficiency) and hence as discussed earlier when analyzing the impact of capacity on variable cost, performance will increase due to an increase in productivity and quality, which will lead to a decrease in unit cost due to scale of lower defects. As performance, quality and novelty increase the competitive strength of the data center increases and hence competition decreases. Unlike capacity we assume that when performance increases, this is partially due to an increase in efficiency and hence a drop in energy consumption. We also assume that an increase in performance is a result of increase in productivity and hence will lead to an increase in revenue and funds.

As quality, resiliency, reliability and processes and procedures increase they all cause variable costs to decrease, and performance to increase. Quality, reliability and resiliency all improve the perception of the data center as they increase and hence do cause a corresponding change to the data center environment as well as the interest of the stakeholders. As reliability and resiliency increase quality improves so the casual relationship. The 
same applies to recurring experience as it becomes more predictable and dependable. Resiliency causes reliability to change in the same direction. We assumed that as resiliency improved more modes of recovery and hence operations have to exist, and hence resiliency causes the mode of operation of the data center to follow its behavior.

Novelty leads to innovative ideas that tends to solve issues and remove negative experiences; hence we assume that as novelty increases the quality of the data center will increase as well as its ability to be a driver or catalyst in the organization for new initiatives, and that novelty causes quality to follow its behavior in the same direction. As novelty increase the services offered by the data center or the output that the various stakeholders are accustomed to receive could vary. This will cause recurring experience to move in an opposite direction from novelty. Novelty will also improve the competitive edge of the data center and reduce the energy consumption for the same unit output. Novelty will cause mode of operation, processes and procedures, interests and ideas to behave in the same direction as novelty moves.

As the data center becomes a driver for new initiatives it forces the organization to increase its capacity and as a result performance. Novelty also can be a catalyst of change. Becoming a driver for new initiatives also causes new internal ideas by the data center staff to emerge and hence intellect follows driver/catalyst variable. Stakeholders also will be more likely to propose ideas, and suggestions as the data center becomes a driver for initiatives that affect these stakeholders. We also assume that with the increase in initiatives and being a catalyst, the fixed costs incurred will increase as new investments are made to support the initiatives.

Retention causes the service to have a longer lifetime and reduces waste hence we notice that life-cycle and environment both follow the same direction as retention. Energy consumption decreases with retained data center products and services and hence follows opposite direction from retention. We assume that as retention increases the stakeholders' interest increase as a result of positive impact on the environment and more value due to a longer ownership period of a data center service output.

Recurring experience causes an improvement in the learning process at the data center and hence we expect that performance, reliability, resiliency, novelty and intellect to move in the same direction as recurring experience. Additionally as recurring experience increases the stakeholders of the data center experience a consistent level of quality and ambiguity decreases causing an increase in loyalty and decrease in competition. It will also cause an increase in stakeholder interest in the data center. The stakeholders will rarely suggest improvements or ideas to the data center staff as long as they receive service that is similar to and recurring with past experience, as a result recurring experience causes ideas to change in an opposite direction. Furthermore, the longer the lifetime of an output product or service the less the variable cost incurred by the data center. On the other hand, as the useful life of the service increases the stakeholder's recurring experience will increase.

Intellect of data center staff and management will cause a change in the same direction to reliability, resiliency, novelty, driver/catalyst and retention as a result of additional knowledge acquired and optimized service design. The more knowledge the data center staff have about the various subsystems the more efficiently they can operate the data center and activate the various modes of operation, hence we will assume that mode of operation will increase with an increase in intellect. Additionally, the level of training and knowledge that the staff possesses will impact the life of the various subsystems, hence a change in intellect causes a corresponding change to the lifetime of the data center subsystems in the same direction. Data center management intellect could influence the way the data center is perceived and could influence decisions throughout the enterprise. We assume that a change in intellect will cause a corresponding change in the perception and environment in which the data center operates. Moreover, it will cause a change to decision making and will lead to a corresponding change in availability of funds through the intellectual negotiation and marketing of the data center with executives at the enterprise. Data centers that are more intellectually mature will tend to have more processes and procedures documented and formalized to ensure a repeatable experience.

Although mode of operation affects variable cost we cannot assume that the more modes of operation we have the more variable cost will occur, so we will deal with the causation through the energy consumption variable. Mode of operation will cause corresponding changes to performance. We will assume that as the mode of operation 
becomes more efficient, performance will increase. As modes of operation increase, the reliability and resiliency of the data center will increase due to the fact that a larger number of operational states are available which will cause an increase in the likelihood of a stable state. Mode of operation will cause an increase in processes and procedures such as shutdown, standby, on-line and off-line.

The life cycle of the various data center elements are affected by environmental factors such as temp and humidity. Similarly, changes in energy costs will be caused by changes in environment. Perception of the data center as seen by others will cause funding to the data center to increase or decrease. As positive perception increases, funding will increase. The competitive landscape affects the data center, as competition increases it will cause an increase to staff salaries and hence variable cost. As competition increases stakeholders will be less interested in the data center and will be more interested in the market leader data center. Economic conditions will affect the Consumer Price Index (CPI) and hence causes changes to variable cost in the same direction. Changes in economic conditions will cause changes to the mode of operation in the same direction. For example as business demands decrease the data center might operate on a reduced schedule. Funding is dependent on revenues and investments hence a decrease in favorable economic conditions will cause a decrease in funding. Economic conditions affect the stakeholders buying power and hence their interest in the data center.

Energy consumption will cause a change in variable cost in the same direction. As funds change we expect quality to change in the same direction, as well as fixed costs in the form of investments. A change in processes and procedures will cause a change in the data center service quality and recurring experience in the same direction. Interest in data center services will affect the perception of data centers, funding and the emergence of ideas to improve the data center. If there is no interest in data centers and its trade publications, less revenue will occur and hence less funding, and data center will develop a weaker perception in the industry. Ideas from stakeholders will cause novelty and intellect to improve and will improve the data center's position as a driver or catalyst. Investments in the data center in the form of fixed costs will cause an increase in capacity and size and a decrease in cash flow and funds.

\section{DATA CENTER STAKEHOLDER}

A typical enterprise data center can have a diverse set of stakeholders such as the IT users at the enterprise, the data center equipment supplier, the executive management, customers of the enterprise, data center staff, other IT departments, enterprise business partners and the list can vary depending on the industry type and organization size and service scope. Figure 5 illustrates the possible stakeholders for an enterprise data center. The definition of each of these groups and a discussion on how these groups are stakeholders in the data center is provided below.

Customers - The customers of any organization are the major stakeholders. In the case of an enterprise the customer of the organization could be internal or external. In this report we refer to customer as the enterprise's external customer. The data center's internal customer is referred to in this report as "Users." An enterprise customer interacts in several ways with the enterprise's data center. Examples are the cases of receiving billing statements from the enterprise, or making payments to the enterprise, checking the status of an order, browsing the website, placing an order for new goods, or completing a preferred customer application. The customer's experience with the data center will be affected by the quality of the statements received in the mail, the accuracy of the data on the statements, the response time by requesting a specific web page and several other metrics.

Investors - Investors of the data center could be internal business units which spend portion of their annual budgets on data center improvements, projects or expansions. Investors could also be enterprise investors such as venture capitalists, bankers, public shareholders or taxpayers depending on the type of the enterprise. In all cases investors' interest focus on a number of common metrics such as return on investment, growth ratios, service costs, expenses and cash flow. Internal investors also have an interest in realizing a business solution or improvement which will result in positive cash flow, reduced expenses or higher growth rates in their own business units. 
Figure 5

Enterprise Data Center Stakeholders

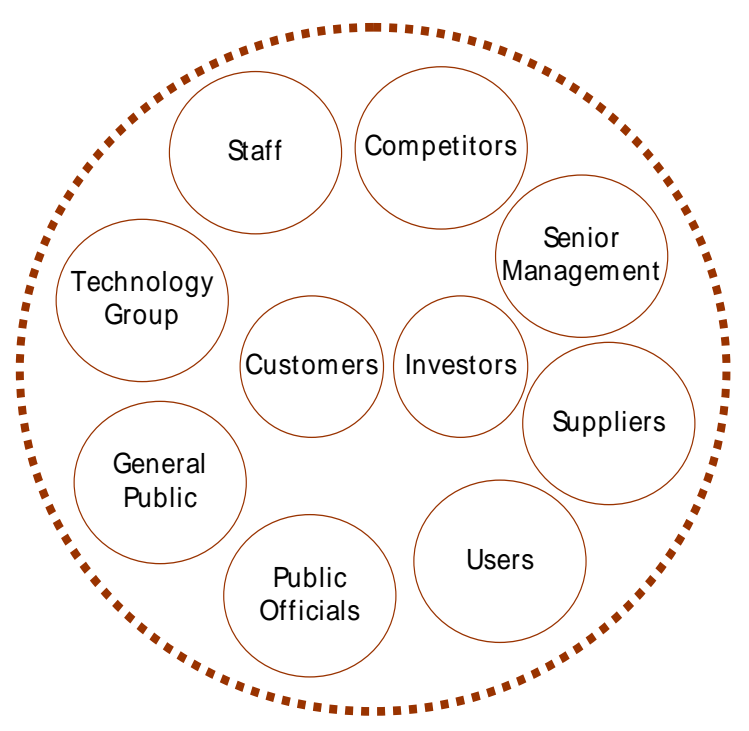

Staff - The data center staff not only has an interest in the data center from a work perspective but also a growth opportunity for long term benefits. The staff's interests are in reduced workload, higher automation, reduced errors and higher retention. These interests could drastically change depending on the culture of the enterprise and many other factors. For example in one enterprise data center staff might be very keen on automating repetitive operational tasks to provide themselves with the opportunity for growth and learning more about newer technologies. In a different enterprise, data center staff could be reluctant to automate services from fear of losing job security.

Senior Management - Senior Management realize that in an information based economy the data center is the heart of the organization, and hence they have a strong interest in its safety, security, integrity and availability, with the least cost and expense.

General Public - As all other stakeholders, the data center is a source of information and knowledge about the enterprise or its core business. However the general public is unique in the fact that its only interest in the data center is in the information the data center processes and present to the public. This is especially true in public or government data centers, news outlets, weather centers and emergency relief agencies.

Users - These are the internal customers, employees of the same organization that work in other business units or departments. Users typically utilize the data and information the data center processes for the user community.

Suppliers - The enterprise's suppliers provide the data center with equipment, software, furniture, data storage media, printing supplies, network services, telecommunications and other types of services and products. Suppliers have an interest in the growth of the data center.

Public Officials - Public officials interest in the data center come in the form of accuracy of information, availability, employment needs and trends, and in the case of public organizations, the effectiveness of taxpayer dollars spending.

Technology Group • The various technology groups in the enterprise has a direct involvement in the everyday issues of the data center, such as network availability, server stability, data feeds, application operation and 
deployments within the data center. A data center uses circuits and feeds designed and supported by a technology network group, and hosts and operates applications developed by the software development group. The security group also works closely with the data center to secure data, systems and applications.

\section{PRIORITIZATION AND WEIGHTING}

The attributes and conditions chosen for the case study are prioritized as illustrated in Table 1 along with the rationale for the selected prioritization. Bear in mind that attribute variables are: capacity, resilience, reliability, availability, performance, and intellect. The relevance conditions are: processes and procedures, and environment.

Mixed Qualitative-Quantitative Analysis - As noticed from the prioritization scheme developed in Table 1, the need for both qualitative analysis to account (for areas such as perception, staff morale and other soft variables) as well as quantitative analysis (for more hard variables such as availability of certain systems and services) is needed. It should also be noted that many soft variables could be assessed by measuring quantifiable certain metrics that reflect how these soft variables change. The final value proposition analysis however should not be narrow-focused and limited only to numbers resulting from the quantitative analysis, but a qualitative assessment should be performed using inductive reasoning through the usage of heuristics for instance.

Heuristic theory has been used extensively in decision making at various levels of complexity. Rechtin and Maier $(2002,2005)$ subscribe to the explicit heuristic theory and have published a list of heuristics as guidelines for architecting a system, and have used them in several ways most notably as a tool to expand the architect's thought paths, a documentation tool of experience, and a guide to progressive rationalization and formalization. These concepts and methods could be extended to a data center.

\section{AN APPLICATION OF 3DVP TOOL TO A COMMUNITY COLLEGE DATA CENTER}

In this section, we will apply the 3 dimensional value proposition (3DVP) method to a community college data center. The community college is located in the State of Maryland and has an annual student enrollment of approximately 45,000 students. To preserve the anonymity of the college we will refer to the College as Learning Community College (LCC).

The Total Cost Ownership Model - Currently, LCC's technology services have been following a purely basic financial model for project justification and valuation. The model used at LCC is the total cost of ownership model (TCO). While TCO is of extreme benefit to ensure that projects fit within available budgets and easier to measure, it is very blind-sighted and cannot satisfy the needs of the LCC initiatives and goals. Financial metrics are inflexible and do not convey the true value of operations-oriented systems and does not reflect the actual performance of areas such as customer service, quality, potential growth and lost opportunity.

TCO is beneficial from a financial controller's perspective whose interest as a stakeholder is to ensure that organization has positive cash flow at all times. Using TCO as the sole and only project justification method is fatal and catastrophic. It neglects the interests of all other stakeholders at LCC including students, faculty, staff, and various others. In many cases, projects might not get funded at all and result in extreme lack of efficiency, poor performance and quality. One example of a project that did not get funded yet had very high significance is the Batch Processing Scheduler (BPS). This project had a TCO of $\$ 15,000$ the first year and $\$ 3000$ each year thereafter. The batch-processing schedule cost LCC roughly $\$ 45,000$ a year in personnel wages to develop and maintain by manually developing it. The batch schedule however was late most of the time, contained errors and inconsistent. Several improvements over the course of 18 months have been done to the manual scheduling process which resulted in huge reduction in error rate, improved documentation and enhanced communications greatly between the data center staff and the application developers. Quality however was still unpredictable, and reliability was not guaranteed. It was extremely difficult for the data center manager to commit to any service levels and service quality, and to outcome was highly dependent on staff intellect, skills, and productivity rates. 
Table 1

Prioritization Of The Most Relevant Data Center Attributes And Conditions

\begin{tabular}{|c|c|c|}
\hline Variable & Priority & Rationale \\
\hline Performance & 1 & $\begin{array}{l}\text { Performance is the main variable used by others in the enterprise to assess and measure the data } \\
\text { center. Performance automatically accounts for availability, resiliency, reliability, efficiency of } \\
\text { processes and procedures, levels of expenditures and service quality. Performance also affects } \\
\text { stakeholder perception and staff morale hence reflects on both environment and intellect. }\end{array}$ \\
\hline Reliability & 2 & $\begin{array}{l}\text { Stakeholders expectations about certain services are of extreme importance. Once a service-level } \\
\text { agreement is not achieved by the data center, it realizes a huge loss in stakeholder credibility, the } \\
\text { recovery which will require not only achieving current service-level agreements, but even } \\
\text { exceeding them. }\end{array}$ \\
\hline Availability & 3 & $\begin{array}{l}\text { Although availability is a main contributor to productivity and hence performance, stakeholders } \\
\text { are not concerned how available the data center is, what is more important to them is the } \\
\text { availability of the services they use when needed, that is why we have placed availability and } \\
\text { resiliency at a lower priority level than reliability. }\end{array}$ \\
\hline Resiliency & 3 & $\begin{array}{l}\text { Data center resiliency is unlikely to be required at all times, however its absence could have severe } \\
\text { short term impacts which could have long term impacts on the environment. }\end{array}$ \\
\hline Environment & 4 & $\begin{array}{l}\text { Environment comprises of external factors to the enterprise which are not always very critical, and } \\
\text { the most important internal factors are enterprise politics, stakeholder perception (a direct value } \\
\text { proposition influencer), and funding decisions. Since data center is heavily technology driven, the } \\
\text { availability of continuous stream of funds for upgrades and improvements is crucial. }\end{array}$ \\
\hline $\begin{array}{l}\text { Processes } \\
\quad \text { and } \\
\text { Procedures }\end{array}$ & 5 & $\begin{array}{l}\text { Processes and procedures contribute to operational and managerial efficiency and hence reflect on } \\
\text { performance. This variable also reflects the level of organization of the data center and provides } \\
\text { the stakeholders with a sense of professionalism of the data center. }\end{array}$ \\
\hline Intellect & 5 & $\begin{array}{l}\text { Data center intellect is another variable that can improve the data center's and professional image } \\
\text { from a stakeholders' perspective again affecting levels of funding, and overall value proposition. } \\
\text { Intellect also controls how well adapted the data center is to deal with novel situations, incidents } \\
\text { and how efficient it is in learning, which are areas that affect performance. }\end{array}$ \\
\hline Capacity & 6 & $\begin{array}{l}\text { Capacity is important from the standpoint of the total service requested and the ability of the data } \\
\text { center to process this request during a certain period. However its impact is not too high on value } \\
\text { proposition mainly due to the fact that service-level agreements are mostly defined at levels below } \\
\text { the full capacity, and stakeholders have agreed to these levels of productivity and performance. }\end{array}$ \\
\hline
\end{tabular}

The project was rejected based on a TCO and total budget availability basis. Had the technology administration assessed the BPS acquisition from a complete value proposition perspective, the decision to acquire the tool might have been different. From an attribute perspective of the BPS we see that the BPS has several key attributes mainly: reliability, resiliency, quality, performance, variable cost and various others. Focusing on these few attributes we can see that BPS could improve data center reliability and will ensure that output services get delivered when expected and as expected, it would eliminate problems such as missing a job in a payroll batch stream which could have severe ramifications such as incorrect check printing, or unbalanced accounting files. It also will ensure consistent and reliable delivery of periodic reports by eliminating errors of running more or less reports due to the reliance on a manual calendar, and the list continues. The BPS example provides an example of how project justification is totally ad-hoc and extremely narrow-sighted using the TCO method, and not looking into the value proposition.

Attributes of Learning Community College Data Center - LCC's data center is a $1250 \mathrm{sq} \mathrm{ft}$ raised floor data center, located on the first floor in one of the main campus buildings. It has secure, yet uncontrolled access. The main enterprise server is an IBM S/390 hosting the core student services (enrollment, registration, classroom 
scheduling, financial aid, student retention, teacher evaluation, student grading, student accounting and transcript services), and enterprise services (accounting, payroll, benefits and human resources) applications. LCC has 5 fulltime data center specialists performing operations (monitoring, processing, incident escalation, reporting and documentation), and there is a daytime supervisor, manager, and technician.

Main services provided are hosting student services and enterprise applications, hosting academic applications, library system, web servers, remote access servers and interactive voice response (IVR) system and web interface for student registration. Batch job processing, report printing, payroll check processing, student grades processing and grade card printing, mailers printing for events, advanced notices, data backup, archival and restore, system performance and availability monitoring, optical scanning of student exams and teacher evaluations, user support, file transfers, data entry and documentation, human resource planning and allocation, service demand forecasting, capacity planning and resource optimization.

Attribute Metrics. The various LCC data center attributes and metrics used here are based on the Technology Services Performance Metrics (2005). The metrics combine both qualitative and quantitative variables and try to eliminate TCO deficiencies. The metric details are: ratio of wasted (unusable) paper to overall paper consumption, online storage utilization, percentage of IVR users hanging up, rate of on-time delivery of reports, total number of times UPS switched to battery due to utility power loss, ratio of available to unavailable services between the hours of data center operation, data center staff knowledge contribution rate, data center process improvement, problem resolution time, staff learning rate, CPU cycles density, maximum man hours, maximum online storage capacity, and printing capacity.

Conditions of Learning Community College Data Center - Table 2 provides details of the selected LCC data center conditions and associated metrics that could be used to measure the value of these conditions.

Table 2

Selected Conditions Considered In The LCC 3DVP Data Center Analysis

\begin{tabular}{|c|c|c|}
\hline Variable & Current Attribute Details & $\begin{array}{l}\text { Metrics to be Used for an } \\
\text { assessment using the 3DVP } \\
\text { approach }\end{array}$ \\
\hline Environment & $\begin{array}{l}\text { LCC investment into its data center over the past } 10-15 \text { years has } \\
\text { been minimal. The main enterprise server is outdated and no longer } \\
\text { supported by the vendor, and software applications are } \\
\text { cumbersome, lack user friendliness and not well integrated. One } \\
\text { exception is a recent consolidation of several network servers into a } \\
\text { single blade server and } 2 \text { racks of pizza box servers. LCC also } \\
\text { invested in a consolidated IBM ESS } 800 \text { Storage Server and an } \\
\text { APC } 80 \mathrm{~K} \text { VA Infrastructure UPS. Staff morale was low, and they } \\
\text { have not been receiving adequate training or coaching. Investment } \\
\text { in staff work comfort and ergonomics has not been comparable to } \\
\text { other IT groups. }\end{array}$ & 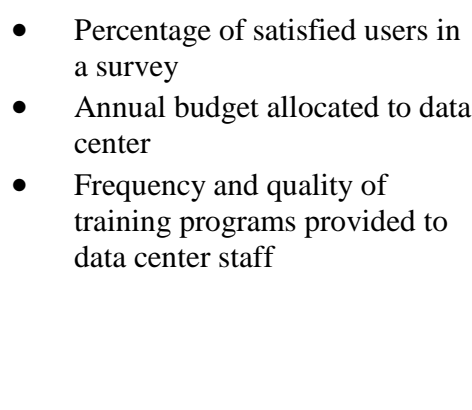 \\
\hline $\begin{array}{c}\text { Processes and } \\
\text { Procedures }\end{array}$ & $\begin{array}{l}\text { Most processes, procedures and operational activities were never } \\
\text { updated or modified over the past } 10-15 \text { years. Only recently have } \\
\text { several processes been documented such as shift turnover, incident } \\
\text { escalation and tracking, power up and shut down, data backup, } \\
\text { configuration change, visitor access and user service request } \\
\text { processes. }\end{array}$ & $\begin{array}{l}\text { - Data Center Process } \\
\text { Improvement (also used to } \\
\text { measure intellect) } \\
\text { - } \quad \begin{array}{l}\text { Scope of improvements to } \\
\text { processes }\end{array}\end{array}$ \\
\hline
\end{tabular}

Learning Community College Data Center Stakeholders • Up to this point we have not mentioned any particular stakeholders in the analysis of LCC's data center value proposition. The 3DVP analysis becomes meaningful only when a stakeholder is considered. Focusing on the student as the stakeholder of choice due to the fact that students 
represent LCC's main "client," source of revenue, and more importantly. LCC's mission which is to serve the educational needs of students. Using student as the stakeholder of interest puts a new perspective on the metrics mentioned earlier. LCC must ensure that metrics reflect a measure of worthiness from the student's perspective. The metrics must be able to provide insight to the contribution of the data center attribute or condition to areas that interest the student. Using the existing literature [EDUCAUSE 2003, Prince George's County Community College 2002 and 2004, and PGCC 2005], we developed the areas of interest from the students' perspective. A list of such areas of interest to students is presented in Table 3.

Table 3

Areas Of Interest To Students, The Main Stakeholder Of The Community College

\begin{tabular}{|c|c|c|}
\hline Goal & Definition & Examples \\
\hline $\begin{array}{l}\text { Learning } \\
\text { Experience }\end{array}$ & $\begin{array}{l}\text { The overall experience and interaction the student } \\
\text { has with the process of learning, including access to } \\
\text { the learning environment, classrooms, curriculum, } \\
\text { instructor availability, instructor performance, } \\
\text { availability of tools and reference material for } \\
\text { studying, learning, exercising and research. } \\
\text { The extent to which the student realizes and } \\
\text { experiences a learning-centered College, and } \\
\text { supports transfer, degree-seeking, professional and } \\
\text { continuing education students }\end{array}$ & $\begin{array}{l}\text { Technology used in teaching in the } \\
\text { classrooms. } \\
\text { Variety and quality of SW applications } \\
\text { available for use } \\
\text { - Availability of references and information } \\
\text { sources }\end{array}$ \\
\hline $\begin{array}{l}\text { Academic } \\
\text { Support } \\
\text { Experience }\end{array}$ & $\begin{array}{l}\text { The overall experience and interaction the student } \\
\text { has with functions supporting the process of learning } \\
\text { including libraries, labs, study groups, and } \\
\text { departmental support }\end{array}$ & $\begin{array}{l}\text { - Technology used in labs, libraries } \\
\text { - } \quad \text { Are departments technology savvy } \\
\text { - } \quad \text { Is there access to study groups, online chat } \\
\text { services } \\
\text { - } \quad \begin{array}{l}\text { Are there student email accounts and disk } \\
\text { space for sharing information }\end{array}\end{array}$ \\
\hline $\begin{array}{l}\text { Administrative } \\
\text { Support } \\
\text { Experience }\end{array}$ & $\begin{array}{l}\text { The overall experience and interaction the student } \\
\text { has with functions supporting the processes of } \\
\text { registration, admission, paying bills, scheduling, } \\
\text { grade reporting, transcript services, bookstore } \\
\text { purchases, check status, confidentiality, privacy and } \\
\text { security of personal information, security services on } \\
\text { campus, rights notification, technology services } \\
\text { (non-academic) }\end{array}$ & $\begin{array}{ll}\text { - } & \text { Adding/Dropping a class } \\
\text { - } & \text { Requesting a transcript } \\
\text { - } & \text { Applying for admission } \\
\text { - } & \text { Checking on the status of a financial aid check } \\
\text { - } & \text { Direct deposit of checks } \\
\text { - } & \text { Direct deductions of payments } \\
\text { - } & \text { Controlling spam on the campus network } \\
\text { - } & \text { Policies of technology use } \\
\text { - } & \text { Notifying students about FERPA requirements }\end{array}$ \\
\hline Access & $\begin{array}{l}\text { The ability to acquire information, transmit } \\
\text { information and share information with staff and } \\
\text { faculty at LCC during various phases of a } \\
\text { relationship with LCC (pre-admission, pre- } \\
\text { registration, pre-classes, during classes, after classes, } \\
\text { after graduation). This includes academic and } \\
\text { administrative information. }\end{array}$ & 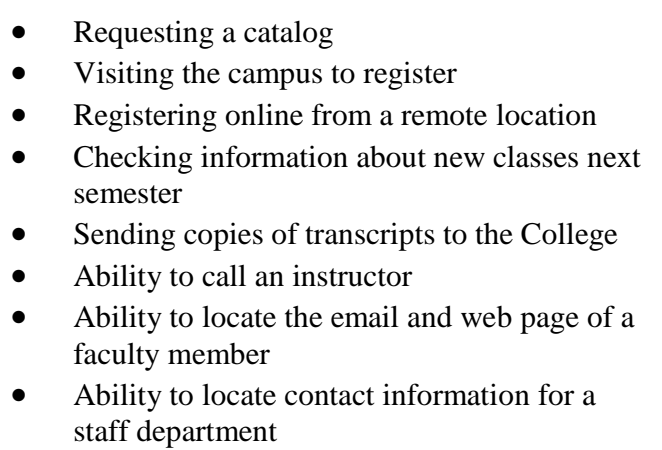 \\
\hline
\end{tabular}




\begin{tabular}{|c|c|c|}
\hline $\begin{array}{c}\text { Services and } \\
\text { Fees }\end{array}$ & $\begin{array}{l}\text { Fees are payments made by students or prospective } \\
\text { students for certain services }\end{array}$ & 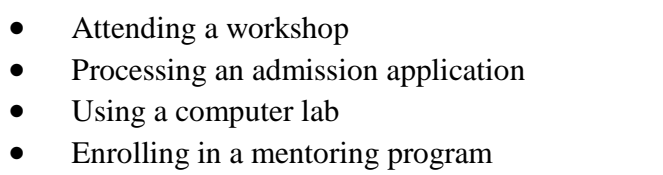 \\
\hline $\begin{array}{l}\text { Professional } \\
\text { Development } \\
\text { experience }\end{array}$ & $\begin{array}{l}\text { The student's experience with programs and } \\
\text { activities related to long-term development and } \\
\text { improvement. }\end{array}$ & $\begin{array}{l}\text { - Career planning, leadership development, } \\
\text { experience and skills development, mentoring } \\
\text { programs, coaching programs, opportunities to } \\
\text { investigate new careers, internships, co-op } \\
\text { programs, work study programs. }\end{array}$ \\
\hline $\begin{array}{l}\text { Educational } \\
\text { offerings }\end{array}$ & $\begin{array}{l}\text { The scope, relevance and significance of educational } \\
\text { programs and options available at LCC or through } \\
\text { LCC }\end{array}$ & $\begin{array}{l}\text { - } \\
\text { - } \\
\text { - } \\
\text { - Number of classes in a particular program } \\
\text { - } \quad \text { Depth of programs in a field/industry } \\
\text { nertificates available } \\
\text { and offerings. }\end{array}$ \\
\hline $\begin{array}{l}\text { Related } \\
\text { educational } \\
\text { activities }\end{array}$ & $\begin{array}{l}\text { Students experience with programs and activities that } \\
\text { are characterized by particular content, focus, } \\
\text { location, mode of delivery or sponsorship }\end{array}$ & $\begin{array}{l}\text { Distance learning, certificates, non-credit } \\
\text { classes, workshops, seminars, debates, invited } \\
\text { industry visits, speaking events, conferences, } \\
\text { industry sponsored training offered at LCC or } \\
\text { through LCC. }\end{array}$ \\
\hline $\begin{array}{l}\text { General } \\
\text { education }\end{array}$ & $\begin{array}{l}\text { The student's experience with general education } \\
\text { areas such as reading, writing, scientific and } \\
\text { quantitative reasoning, critical analysis and } \\
\text { reasoning, technological competency and } \\
\text { information literacy }\end{array}$ & $\begin{array}{l}\text { - Workshops, classes, volunteering sessions } \\
\text { related to these areas. }\end{array}$ \\
\hline $\begin{array}{l}\text { Knowledge } \\
\text { and } \\
\text { information } \\
\text { availability }\end{array}$ & $\begin{array}{l}\text { Student's experience about information availability } \\
\text { and ability to share knowledge inside and outside the } \\
\text { classroom }\end{array}$ & $\begin{array}{l}\text { Information about weather closings, } \\
\text { Information about new classes, Information } \\
\text { about grades, career services }\end{array}$ \\
\hline
\end{tabular}

After analyzing the goals and examples provided in Table 3, the customized metrics and attribute details using 3DVP approach are presented in Table 4.

Table 4

Customized Metrics And Attributes To Reflect The Interests Of Students Of The Community College.

\begin{tabular}{|c|c|c|}
\hline Variable & Modified 3DVP Attribute Detail & Metrics to be Used for a 3DVP Assessment \\
\hline Performance & $\begin{array}{l}\text { LCC data center performance is assessed based on student } \\
\text { feedback using surveys, and incentives are embedded into } \\
\text { the feedback process to encourage students to participate. } \\
\text { Moreover the College uses its strategic access to young } \\
\text { talent to organize contests among students majoring in } \\
\text { business, management and technology programs to solicit } \\
\text { proposals for improved services. Feedback and student } \\
\text { assessments are well documented and received through a } \\
\text { web interface to a simple form emailed to the data center. }\end{array}$ & $\begin{array}{l}\text { - } \quad \text { Quality and readability of grade reports. } \\
\text { - } \quad \text { Accuracy of early alert notices } \\
\text { Disk space available for students to store } \\
\text { work and assignments } \\
\text { - } \begin{array}{l}\text { Percentage of IVR users hanging up and } \\
\text { a breakdown by reason of canceling } \\
\text { transaction }\end{array}\end{array}$ \\
\hline Reliability & $\begin{array}{l}\text { Class registration application, academic applications and } \\
\text { information about student account is available when needed. }\end{array}$ & $\begin{array}{l}\text { Percent of time applications were not } \\
\text { available during advertised hours. } \\
\text { Application response time during } \\
\text { registration periods. }\end{array}$ \\
\hline
\end{tabular}




\begin{tabular}{|c|c|c|}
\hline Availability & $\begin{array}{l}\text { Data center availability is monitored } 24 * 7 \text { using SNMP and } \\
\text { WhatsUp Gold. Upon the failure of a subsystem element an } \\
\text { email message is sent to the appropriate technical staff } \\
\text { alerting the change in state. Tracking availability during } \\
\text { advertised to hours and ensures service requests and } \\
\text { resources agreed upon with stakeholders. Develop a cold- } \\
\text { site or full disaster recovery strategy and plan and test it } \\
\text { frequently. }\end{array}$ & - $\quad$ Service Availability \\
\hline Resiliency & $\begin{array}{l}\text { Dynamic fail-over and redundancy to student services } \\
\text { systems and academic applications. }\end{array}$ & $\begin{array}{l}\text { Total Number. of Times data center } \\
\text { recovered from a minor outage within } 5 \\
\text { minutes, a moderate outage within } 30 \\
\text { minutes and a severe outage within } 4 \\
\text { hrs. }\end{array}$ \\
\hline Intellect & $\begin{array}{l}\text { Motivation is increased through active participation in } \\
\text { developing optimized data center processes and services to } \\
\text { serve student needs and interests. Customized goals in the } \\
\text { staff performance evaluation focuses on specific student } \\
\text { needs and can be directly mapped to student goals. }\end{array}$ & $\begin{array}{l}\text { - Staff understanding and realization of } \\
\text { students' data and information needs. } \\
\text { - Staff understanding of students' } \\
\text { priorities and goals. } \\
\text { - } \quad \text { Percentage of resources committed by } \\
\text { data center staff to knowledge sharing } \\
\text { particularly areas related to student } \\
\text { services and academic programs. } \\
\text { - Learning rate of data center staff }\end{array}$ \\
\hline Capacity & $\begin{array}{l}\text { Capacity is well known, defined and maintained on a } \\
\text { quarterly basis. }\end{array}$ & 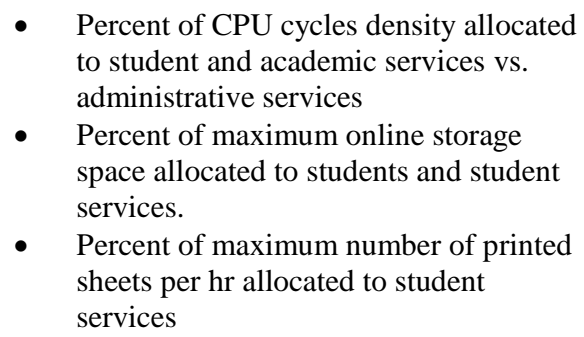 \\
\hline
\end{tabular}

\section{MIXED QUALITATIVE - QUANTITATIVE ANALYSIS}

By measuring the metrics outlined in Tables 1-3, one can obtain quantitative data to assess the attributes and conditions of the data center. Using heuristics and qualitative analysis introduced by the 3DVP approach and reflected to some extent in the metrics in Table 4,we can have a more accurate understanding of the value of the data center to the Community College from the perspective of the student. By repeating the same exercise at another point in time $\left(\mathrm{t}_{1}\right)$ during the academic year we might notice a difference in the metrics as a result of changes in students' interest at time $t_{1}$ from what it was originally at time $t_{0}$. This also support the hypothesis presented on page 4, assuming the data center's value proposition is function of a set of relative variables identifying its characteristics, and the conditions in which it operates. An analysis of these variables to study dependencies can reflect the worthiness or importance of the data center to a specific stakeholder of the data center at a specific point in time.

\section{CONCLUSION}

There are many methods to define the value proposition of a service organization such as a data center. Quantitative methods while using rigid scientific foundations and complex equations could miss valuable perspectives due to the lack of soft elements contributing to the overall value of the data center. On the other hand a purely qualitative approach lacks measurements of collected service metrics from the field and could focus on the wrong elements contributing to data center value proposition. An approach which considers both hard and soft attributes can incorporate soft factors as well as account for hard measurements resulting in a much more 
comprehensive assessment which includes clearly visible as well as more subtle value contributors. It also allows for tailoring of the value proposition based on stakeholder and time. The key contribution of this paper to the current body of literature is that it consider and incorporate the qualitative and quantitative approaches by using the three dimensional value proposition too (3DVP).

\section{ACKNOWLEDGEMENTS}

This research is funded by the Virginia's Center for Innovative Technology, James Madison University.

\section{REFERENCES}

1. Theo Renkema, The IT Value Quest: How to Capture the Business Value of IT-based Infrastructure, John Wiley, 2000.

2. Michael Shenkman, Value and Strategy: Competing Successfully in the Nineties, Quorum Books, 1992.

3. Robert Kaplan and David Norton, The Balanced Scorecard - Measures that Drive Performance, Harvard Business Review, January 1992.

4. P.B Checkland, From Optimizing to Learning: A development of systems thinking for the 1990's, Journal of the Operational Research Society, Volume. 36, Page 757-767.

5. J. Rosenhead, Rational Analysis for a Problematic World: Problem Structuring Methods for Complexity, Uncertainty and Conflict, Wiley, 1989.

6. W Orlikowski and J Baroudi, Studying Information Technology in Organizations: Research Approaches and Assumptions, Information Systems Research, Volume. 2, Number 1, Page 1-28, 1991.

7. Josh Lerner, Venture Capital and Private Equity, John Wiley, 2000.

8. Janet Smith and Richard Smith, Entrepreneurial Finance, John Wiley, 2000.

9. Louise Elliott, An inside look at today's data centers, Design News, http://www.designnews.com/article/CA181391.html, November 19, 2001.

10. Robert Kaplan and David Norton, The Balanced Scorecard: Translating Strategy into Action, Harvard Business School Press, September 1996.

11. Robert Kaplan and David Norton, The Strategy-Focused Organization: How Balanced Scorecard Companies Thrive in the New Business Environment, September 2000.

12. Alice Stewart and Julie Carpenter-Hubin, The Balanced Scorecard: Beyond Reports and Rankings, Planning for Higher Education, Winter 2000-2001.

13. Brent Ruben, Toward a Balanced Scorecard for Higher Education: Rethinking the College and University Excellence Indicators Framework, Higher Education Forum, http://www.qci.rutgers.edu, Fall 1999.

14. Federal Chief Information Officers Council, Best Practices Committee, Community of Practice for IT Performance Management, Lessons Learned on Information Technology Performance Management: Applying the Balanced Scorecard and Applied Information Economics to Federal Information Technology Initiatives, Federal Chief Information Officers Council, May 2001.

15. Douglas Hubbard, Overview of the Applied Information Economics, http://www.hubbardresearch.com/overview.htm, March 2005.

16. W. Grey, et. al, An Analytical Approach for Quantifying the Value of E-business Initiatives, IBM Systems Journal, Volume 42, Number 3, 2003.

17. Michael Porter, Competitive Advantage: Creating and Sustaining Superior Performance, Free Press, 1998.

18. Ayman Nassar, Product Value Proposition: A Step by Step Approach, Intercontinental Networks White Paper, April 2003.

19. Adamantios Diamantopoulos and Judy Siguaw, Introducing LISREL, Sage Publications, 2000.

20. Harold Kurstedt, It's About Systems Thinking leading to Effective Actions, INCOSE Tutorial, April 23, 2005.

21. A. C. Rosander, Deming's 14 Points Applied to Services, Marcel Dekker, ASQC Quality Press, 1991.

22. American Society for Quality, Reliability, http://www.asq.org/learn-aboutquality/reliability/overview/overview.html, November 2005.

23. John Sterman, Business Dynamics: Systems Thinking and Modeling for a Complex World, Irwin McGrawHill, 2000. 
24. Mark Maier and Eberhardt Rechtin, The Art of Systems Architecting, CRC Press, 2002.

25. Mark Maier, Systems Architecting, INCOSE Workshop, Dec 10, 2005.

26. EDUCAUSE, The Student Guide to Evaluating Information Technology on Campus: What You Need to Know and What You Should Ask When Choosing a College or University

27. Prince George's Community College, The Learning-Centered College Committee, Recommendations for Strengthening the Learning Culture of Prince George's Community College, July 9, 2002.

28. Prince George's Community College, Technology Services Fiscal Year 2005: Institutional Operational Objectives, Sept 2004.

29. PGCC, Middle States Self Study, 2005.

30. PGCC, Technology Services Performance Metrics, April 2005.

\section{NOTES}


NOTES 